\title{
PRESTAÇÃO DE SERVIÇO EM DESIGN PARA PRODUÇÃO DE OBJETOS DE APRENDIZAGEM: RELATO E REFLEXÕES SOBRE PROCESSOS DE CRIAÇÃO
}

\author{
RECIFE/PE MAIO/2018 \\ Manuela César de Arruda Pedrosa $\quad$ - IBRATEC - manuelacesarap@gmail.com \\ Tipo: Relato de Experiência Inovadora (EI) \\ Categoria: Métodos e Tecnologias \\ Setor Educacional: EDUCAÇÃO INFANTIL E FUNDAMENTAL, EDUCAÇÃO MÉDIA E \\ TECNOLÓGICA, EDUCAÇÃO SUPERIOR, EDUCAÇÃO CONTINUADA EM GERAL
}

\begin{abstract}
RESUMO
Buscando seguir as tendências mundiais e trazer cada vez mais interatividade para o Ensino a Distância, o Objeto de Aprendizagem é cada vez mais utilizado e adaptado à diversas necessidades, mas, no âmbito do Design ele é pouco trabalhado, tanto academicamente quanto profissionalmente, esse artigo busca trazer, através do olhar de uma Estudante de Design e prestadora de serviços para uma Editora focada para EAD, uma síntese do processo de produção dos Objetos, buscando criar um paralelo entre os princípios utilizados e os métodos que foram desenvolvidos.
\end{abstract}

Palavras-chave: Objetos de Aprendizagem; Design; Processo de Criação

AGRADECIMENTOS

A MINHA MÃE QUE É FONTE DIÁRIA DE INSPIRAÇÃO E À EDITORA, QUE ABRIU AS PORTAS PARA MIM. 


\section{INTRODUÇÃO}

Os processos envolvidos na produção de Objetos de Aprendizagem para Educação a Distância são por vezes pouco explorados e compreendidos por aqueles que, como eu, estão adentrando no universo de uma modalidade de Ensino contributiva e que está revolucionando a maneira como enxergamos a construção do aprendizado.

Tendo trazido um novo folego para o ensino, o EAD, através de ferramentas, busca tornar essa dinâmica professor/aluno/sala de aula mais colaborativa, e um método explorado para isso é o objeto de aprendizagem, que, seguindo as tendências do mundo cada vez mais "gamer" busca trazer novos desafios, sendo uma maneira de tornar a experiência do aluno mais divertida e interativa.

Neste artigo abordarei, com base na minha experiência como prestadora de serviço para uma editora e estudante de Design Gráfico, os processos que presenciei na criação da interface gráfica de Objetos de Aprendizagem, buscando englobar todas as etapas que vão desde a interação com o conteudista até a criação do Design que é utilizado no Objeto.

\section{PROBLEMA DE PESQUISA}

O Design aplicado à educação não é um conteúdo que aprendemos na graduação, e a falta de conhecimentos básicos sobre a dinâmica de criação para esta aplicação tornase um problema quando temos a oportunidade de prestar serviço ou estagiar neste segmento. O primeiro foi o de pesquisa e buscar suporte no setor que poderia nortear nossas ações: o designer instrucional.

Minha principal tarefa na prestação de serviço em tela era desenvolver todas as peças gráficas que alimentaria a esteira do desenvolvedor de TI na produção de Objetos de Aprendizagem.

Sendo um instrumento que é cada vez mais utilizado e vem para somar ao ensino não só a distancia, o Institute of Electrical and Electonics Engineers (IEEE) definiu, em 2000, objetos de aprendizagem como "uma entidade, digital ou não digital, que pode ser usada e reutilizada ou referenciada durante um processo de suporte tecnológico ao ensino e aprendizagem.", tendo essa definição em mente, é preciso compreender que o processo de criação de um objeto deve ser coeso e bem elaborado desde o primeiro 
passo.

\section{JUSTIFICATIVA}

\section{Objetivos}

Por vezes os processos que permeiam a criação dos objetos de aprendizagem podem ficar em um âmbito nebuloso e pouco trabalhado na prestação de serviços de criação, mas, sendo cada vez mais difundido é importante atentar quanto a metodologia empregada para o desenvolvimento, bem como para ao que o objeto é direcionado.

O objetivo deste artigo é trazer uma interconexão entre o processo de criação do OA com alguns princípios do Design, em especial com o estudo da Usabilidade e da experiência do usuário.

\section{Objetivo Geral}

Relatar a experiência como prestadora de serviço em design gráfico na produção de Objetos de Aprendizagem.

\section{Objetivos específicos}

- Apresentar as dificuldades

- Discorrer sobre Objetos de Aprendizagem

- Relatar o fluxo de atividades do serviço.

\section{FUNDAMENTAÇÃO TEÓRICA}

Uma ferramenta de ampla aplicação e que pode ser utilizada conforme a necessidade, o Objeto de Aprendizagem (AO) é adaptável, podemos observar isso em um trecho do artigo Aprendizagem Matemática em Contextos Significativos: Objetos Virtuais de Aprendizagem e Percursos Temáticos, de SPINELLI:

\footnotetext{
Um objeto virtual de aprendizagem é um recurso digital reutilizável que auxilie na aprendizagem de algum conceito e, ao mesmo tempo, estimule o desenvolvimento de capacidades pessoais, como, por exemplo, imaginação e criatividade. Dessa forma, um objeto virtual de aprendizagem pode tanto contemplar um único conceito quanto englobar todo o corpo de uma teoria. Pode ainda compor um percurso didático, envolvendo um conjunto de atividades, focalizando apenas determinado aspecto do conteúdo envolvido, ou formando, com exclusividade, a metodologia adotada para determinado trabalho. (SPINELLI, BRASIL, 2015)
}

Por conta dessa alta adaptabilidade podem existir diversos processos de criação, mas 
existem alguns parâmetros básicos que devem ser seguidos para um objeto claro e funcional, um deles são os atributos trazidos pelo CAREO[1] (2001), um dos maiores repositórios de Objetos de aprendizagem, esses atributos são:

- Modularidade (Modularity): Segundo o CAREO "Os objetos devem ser livres, coerentes por si mesmo, unitários e não sequenciais", demonstrando que o objeto deve ser um "sistema" fechado, que faça sentido por ele mesmo;

- Detectabilidade (Discoverable): Esse aspecto esta voltado para a acessibilidade do objeto, e se refere, principalmente, a facilidade que se pode procurar e achar o mesmo. Para que esse atributo esteja em bom funcionamento deve-se ter uma atenção redobrada quanto os metadados do objeto, aspecto que deve ser conversado com o desenvolvedor que será responsável por cria-los. Esses metadados têm o objeto de tornar mais fácil a organização do Objeto no plano do desenvolvimento do código, caso ele esteja mal empregado o OA ficará confuso e com pouca possibilidade de descoberta.

- Interoperabilidade (Interoperable): Voltado para a responsividade do objeto, a interoperabilidade é a capacidade que o OA tem de se adaptar a diversas plataformas e navegadores diferentes sem perder sua funcionalidade básica. Tárcio Zemel, em seu livro define o design responsivo como:

É aquele web design que responde a quaisquer dispositivos/resoluções e, devido a uma série de características técnicas bem específicas, é bem apresentado em qualquer um deles (ZEMEL, BRASIL, 2015, p.23)

Trazendo uma premissa de acessibilidade e adaptabilidade a rotina do estudante, esse atributo é bastante importante, uma vez que os celulares e tablets, por exemplo, são as ferramentas utilizadas para estudar. Esse atributo se comunica diretamente com a detectabilidade, trazendo a importância do OA ser o mais livre possível, possibilitando assim a difusão maior do mesmo.

Para criar um objeto de aprendizagem funcional e confortável para o usuário, esses atributos são utilizados juntamente com um principio do Design, o da Usabilidade, descrito no livro de Jakob Nielsen e Hoa Loranger como sendo:

\footnotetext{
A usabilidade é um atributo de qualidade relacionado à facilidade do uso de algo. Mais especificamente, refere-se à rapidez com que os usuários podem aprender a usar alguma coisa, a eficiência deles ao usá-la, o quanto lembram daquilo, o seu grau de propensão a erros e o quanto gostam de utilizá-la. Se as pessoas não puderem ou não utilizarem um recurso ele pode muito bem não existir. (NIELSEN e LORANGER, BRASIL, 2007, p.XVI)
}

Buscar a usabilidade no OA é fazer valer os atributos básicos, por isso eles devem andar lado a lado em todo o processo de criação, para isso o Design deve estar 
presente e buscar participar ao máximo de toda a experiência.

\section{METODOLOGIA}

Os atributos norteiam todo o processo desenvolvido do Objeto, uma vez que eles devem ser cumpridos em sua integralidade para que tenhamos um $O A$ coeso e bem estruturado que vai auxiliar o aluno na fixação do conteúdo ou aprendizado de um novo.

Após a observação desses três elementos norteadores, houve a criação de um fluxo de produção que trouxe mais organização e clareza para todo o processo, esse fluxo é descrito abaixo:

Criação de

requisitos
Criação de

projeto gráfico
Desenvolvimento

do código

Imagem 1 - Fluxo na criação do OA

1. Criação dos Requisitos

Em um primeiro momento deve se ter um dialogo com a pessoa que criou o conteúdo do curso, aula ou conteúdo a que o OA se dirige para compreender o que de fato se faz necessário no objeto, nesse momento as redundâncias devem ser evitadas. No atual processo são feitas 5 perguntas, são elas:

- Qual a disciplina a que o objeto se dirige?

- A que público se dirige? (Ensino fundamental, médio, graduação ou pós, por exemplo)

- Qual será sua principal função?

- O objeto será gameficado ou não? (uso de pontuação no OA)?

- Ele irá de alguma maneira testar o conhecimento ou irá apenas trazer alguma informação adicional?

Após essas 5 perguntas básicas, se restar mais algum questionamento um novo diálogo deverá acontecer, caso não, passamos para a criação dos requisitos, para facilitar esse processo fiz uso de uma tabela, criada pela Editora, para dispor as informações do OA, nessa tabela constam os dados básicos das telas que o objeto terá, qual vai ser seu inicio e seu fim, e informações sobre a disciplina e questionamentos acima citados. 


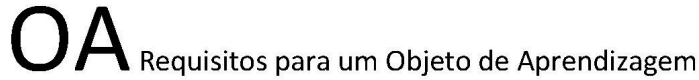

\section{Cliente:}

Curso:

Disciplina:

Sequência do OA:

Gameficado

( ) SIM I ( ) NÃO

Título do OA:

INICIO

TELA INICIAL:

BOTÃO:

$O A$

\begin{tabular}{|c|c|}
\hline \multicolumn{1}{|c|}{ AFIRMATIVA } & \multicolumn{1}{|l|}{ RESPOSTA } \\
\hline TELA DO JOGO 1 & \\
\hline \multicolumn{2}{|l|}{} \\
\hline TELA DO JOGO 2 & \\
\hline & \\
\hline TELA DO JOGO 3 & \\
\hline & \\
\hline TELA DO JOGO 4 & \\
\hline
\end{tabular}

FINAL

FINAL POSITIVO:

FINAL NEGATIVO:

Imagem 2 - Tabela utilizada para detalhar requisitos

2. Criação do projeto gráfico

É nesse momento da produção do Objeto que ele toma forma, e essa forma vai ser vital para que ele cumpra seu papel corretamente, para isso, o designer deve prestar possuir um olhar por vezes técnico, e por vezes de usuário.

Nesta etapa os dados que foram coletados e detalhados na etapa anterior são colocados em um layout, é nesta etapa que ainda é pouco abordada pela literatura cientifica, um dos norteadores foi o livro Não me Faça Pensar, de Steve Krug, nele são dadas algumas lições básicas de usabilidade para a Web, através de premissas, que, 
para o desenvolvimento do OA, resumi em três:

- Não faça o usuário ter de pensar

O layout deve ser intuitivo, isto é, assim que o estudante ou a pessoa que vai utilizar o OA o abrir, ele deve saber onde clicar para iniciar, qual vai ser a mecânica e principalmente qual é o objetivo do objeto. Por conta deste fatores é aconselhável que o layout seja o mais minimalista possível.

- Corte ao máximo o numero de palavras, para deixar um design clean e mais coeso

Todos os textos que estão no OA devem estar ali por algum motivo, não se deve ter excesso de texto ou informações que podem trazer uma interpretação dúbia do usuário. A linguagem utilizada deve ser pensada com atenção, dependendo do objetivo e do publico alvo daquele $O A$, no caso da Editora, para atingir os atributos tratados anteriormente, utilizamos uma linguagem sem rebuscamento mas formal.

- Use apenas os "clicks" necessários.

O número de clicks varia conforme a mecânica do $\mathrm{OA}$, se um objeto tem várias telas ele terá um número elevado, os clicks devem ser distribuídos ao longo do objeto, para que o usuário não canse ou se irrite por clicar muito em algo desnecessário. Esse fator deve ser conversado com o desenvolvedor, afim de chegar em uma quantidade confortável e que não comprometa a funcionalidade.

\section{Desenvolvimento do código}

Na ultima etapa do processo, o desenvolvedor cria, com base no layout criado, o código que torna o objeto funcional, um dos atributos tratados, a detectabilidade, é observada principalmente nesta etapa, o desenvolvedor deve criar uma base de dados coesa e que faça o objeto funcionar sem travas ou bugs, criando um sistema fechado.

\section{CONSIDERAÇÕES FINAIS E CONCLUSÃO}

Ao decorrer deste artigo busquei sistematizar através da minha vivencia como prestadora de serviços para a Editora o processo que envolve a criação de objetos de aprendizagem, trazendo as principais dificuldades e a descrição dos processos e dos norteadores que utilizei em todo o período em que atuei na parte de levantamento de 
requisitos e design.

Compreendendo o processo de maneira geral fica nítido que no desenvolvimento desses objetos de aprendizagem o Design precisa desenvolver uma compreensão mais aprofundada sobre a usabilidade de sistemas e buscar tecer uma série de requisitos básicos para tornar a experiência do usuário mais satisfatória e o aprendizado mais completo.

\section{REFERÊNCIAS}

ZEMEL, Tárcio. Web Design Responsivo: Páginas adaptáveis para todos os dispositivos. São Paulo: 2015.

KRUG, Steve. Não Me Faça Pensar. São Paulo: 2014.

CAREO, 2001, aput FRIESEN, Norman, Interactive Learning Environments, 2001. Disponível em: http://www.careo.org/documents/objects.html. Acesso em: 18/04/2018.

SILVEIRA, Milene Selbach, CARNEIRO, Mára Lúcia Fernandes. Diretrizes para a Avaliação da Usabilidade de Objetos de Aprendizagem, 2012.

AUDINO, Daniel Fagundes, NASCIMENTO, Rosemy da Silva. Objetos de Aprendizagem - Diálogos entre Conceitos e uma Nova Proposição Aplicada à Educação, 2010

LORANGER, Hoa, NIELSEN, Jakob. Usabilidade na Web: Projetando Websites com qualidade. Rio de Janeiro, 2007.

[1] http://www.careo.org/documents/objects.html 